\title{
Dönüşümsel Liderlik, Kişi-Örgüt Uyumu ve İş Tatmini İlişkisi: Kamu Çalışanlarına Yönelik Araştırma (Transformational Leadership, Person-Organization Fit and Job Satisfaction Relationship: A Research on Public Servants)
}

\section{Alev SÖKMEN iD a Osman BENK iD $b$}

a Başkent Üniversitesi, Sosyal Bilimler Meslek Yüksekokulu, Ankara, Türkiye. alev@baskent.edu.tr

b Gümüşhane Üniversitesi, İktisadi ve İdari Bilimler Fakültesi, Gümüşhane, Türkiye. osmanbenk@gumushane.edu.tr

\begin{tabular}{|c|c|}
\hline MAKALE BİLGİSİ & ÖZET \\
\hline Anahtar Kelimeler: & $\begin{array}{l}\text { Amaç - Bu araştırmada dönüşümsel liderlik, kişi-örgüt uyumu ve iş tatmini değişkenleri ilişkisini ortaya } \\
\text { koymak amaçlanmıştır. }\end{array}$ \\
\hline $\begin{array}{l}\text { Kişi-Örgüt Uyumu } \\
\text { İş Tatmini } \\
\text { Kamu Çalışanları }\end{array}$ & $\begin{array}{l}\text { Yöntem - Araştırma verileri Ankara ilindeki bir bakanlığa ait merkez biriminde çalışan } 560 \text { katılımcıdan } \\
\text { anket ile elde edilmiştir. Çalışmada öncelikle geçerlilik ve güvenirlik analizleri yapılmıştır. İlgili } \\
\text { bağımsız ve bağımlı değişkenler arasındaki ilişkileri ortaya koyabilmek ve hipotezleri test edebilmek } \\
\text { amacıyla korelasyon ve regresyon analizleri yapılmıstır. Aracılık etkisini ortaya koyabilmek için hem } \\
\text { Baron ve Kenny, hem de Hayes'in aracılık modellerinden yararlanılmıştır. }\end{array}$ \\
\hline $\begin{array}{l}\text { Gönderilme Tarihi } 22 \text { Mart } \\
2020 \\
\text { Revizyon Tarihi } 9 \text { Mayıs } \\
2020\end{array}$ & $\begin{array}{l}\text { Bulgular - Yapılan korelasyon analizine göre dönüşümsel liderlik ile kişi-örgüt uyumu ve iş tatmini } \\
\text { arasında pozitif yönde anlamlı bir ilişki olduğu tespit edilmiştir. Regresyon analizi sonucunda } \\
\text { dönüşümsel liderliğin kişi-örgüt uyumu ve iş tatmini üzerinde anlamlı bir etkisinin olduğu, kişi-örgüt } \\
\text { uyumunun da iş tatmini üzerinde anlamlı bir etkisinin olduğu görülmektedir. Bununla birlikte araştırma } \\
\text { bulguları dönüşümsel liderliğin iş tatmini üzerindeki etkisinde kişi-örgüt uyumunun kısmi aracıllk } \\
\text { etkisinin olduğunu da göstermektedir. }\end{array}$ \\
\hline $\begin{array}{l}\text { Makale Kategorisi: } \\
\text { Araştırma Makalesi }\end{array}$ & $\begin{array}{l}\text { Tartışma - Bir bakanlıkta görev yapan } 560 \text { kamu çalışanından elde edilen bulgular değerlendirildiğinde } \\
\text { merkezi ve taşra teşkilat yönetiminin çağın gerektirdiği dönüşümsel çabalarla birlikte çalışanların kişi- } \\
\text { örgüt uyumlarını dikkate almaları ve iş tatmin düzeylerini artırmaya yönelik eylemlerde bulunmaları } \\
\text { gerektiği düşünülmektedir. Bu tarz örgütler kontrol odaklı bir yaklaşımla sürecin en başından itibaren } \\
\text { örgütleri ile uyumlu olan veya bunun geliştirilebileceğine inandıkları kişileri seçmelidirler. İzleyeninin } \\
\text { kişisel bir sorununa eğilen, onu öven ve ona rehberlik eden bir lider çalışanın iş tatminine } \\
\text { yadsınmayacak düzeyde etki edebilir. Gelecek çalışmalar için kamu veya özel örgütler arasında } \\
\text { karşılaştırmalı olarak değişkenlerin tekrar ele alınması literatüre katkı sunulması adına faydalı olabilir. }\end{array}$ \\
\hline
\end{tabular}

\begin{tabular}{ll}
\hline ARTICLE INFO & ABSTRACT \\
\hline $\begin{array}{l}\text { Keywords: } \\
\text { Transformational }\end{array}$ & $\begin{array}{l}\text { Purpose - It is aimed to reveal relationships among transformational leadership, person-organization fit } \\
\text { and job satisfaction in that research. } \\
\text { Peadership }\end{array}$ \\
$\begin{array}{l}\text { Design/methodology/approach - Research data were collected by survey from } 560 \text { participants who } \\
\text { Jobk at a department of a ministry in Ankara. First of all, in that study validity and reliability analyses } \\
\text { are done. Correlation and regression analyses are done both to reveal the relationships among related } \\
\text { Public Servants }\end{array}$ & $\begin{array}{l}\text { mependent and independent variables and to test hypotheses. Both Baron and Kenny and Hayes } \\
\text { mediation models are used to show mediation effect. }\end{array}$ \\
& $\begin{array}{l}\text { Findings - According to correlation analysis, there is a significant positive correlation among } \\
\text { transformational leadership, person-organization fit and job satisfaction. As a result of regression } \\
\text { analysis, transformational leadership has a meaningful effect on person-organization fit and job } \\
\text { satisfaction and also person-organization fit has a meaningful effect on job satisfaction. However, } \\
\text { research findings show that the effect of transformational leadership is partly mediated by person- } \\
\text { organization fit in the effect on job satisfaction. } \\
\text { Accepted 14 May 2020 } \\
\text { Discussion - When the findings which are derived from 560 public employees working in a ministry } \\
\text { that are evaluated, it is thought that central and rural management of ministry should consider on } \\
\text { person-organization fit of its employees and do some actions to raise their job satisfaction levels by } \\
\text { transformational attempts of today's necessities. These kinds of organizations should select compatible } \\
\text { and developable -of that compatibleness- individuals as they believe from the beginning of the } \\
\text { recruitment process with a control focused approach. A leader, who is interested in individual problems } \\
\text { of followers, praises and guides them, that affects their levels of job satisfaction incontrovertibly. For }\end{array}$ \\
\end{tabular}




\section{Giriş}

Örgütler açısından insan sermayesi en önemli örgütsel kaynaklardan biridir. Çalışanların örgütle olan ilişkisi, yapmakta oldukları işleri önemli bulması ve liderleri tarafından kendilerine değer verilmesi, kişi-örgüt uyumları ve iş tatmini duymaları üzerinde önemli bir etkiye sahiptir.

Örgütsel Davranış ekolünde işyeri psikolojisi alanındaki en çok araştırılan değişkenlerden biri olan iş tatmini, çok sayıda psiko-sosyal sorun, iş dünyasının değişmesi, liderlikten iş tasarımına kadar farklılaşan örgütsel faktörler ile ilişkilendirilmiştir (Park ve Kim,2009).

Liderlik örgüt politikaları ile ilgili algıları etkileyen faktörlerden birisidir ve bu örgüt politikaları, sonuç olarak çalışanların kişi-örgüt uyum düzeylerini etkilemektedir. Dönüşümsel liderler örgütsel politikaları uygun hâle getirme ve sorunları azaltma ve bu yolla kişi-örgüt uyumunu artırma işlevine sahiptirler (Saleem,2015).

Schneider (1987) ASA (Attraction-Selection-Attrition) Model'inde bireylerin örgütlerle uyum içinde olurlarsa onların örgüte çekileceğini, seçileceğini ve elde tutulacağını veya örgütle iyi bir uyum içerisinde değillerse de örgütten ayrılacağını ileri sürmektedir. Hem araştırmacılar, hem de uygulamacılar rekabetçi iş ortamında ve iş gücü piyasasında gerekli olan esnek ve örgüt ile uyumlu iş gücünün elde tutulabilmesi için, kişi-örgüt uyumunun kritik bir rol üstlendiğini ileri sürmektedirler.

Bu bağlamda araştırmanın amacı dönüşümsel liderlik (DL), kişi-örgüt uyumu (KÖU) ve iş tatmini (IT) değişkenleri ilişkisini bakanlık çalışanları örnekleminde ele almaktır. Bu amaç doğrultusunda öncelikle ilgili değişkenler açıklanacaktır. Daha sonra araştırma kısmında ilgili değişkenlerin birbirlerine olan etkileri ortaya konacaktır.

\section{Dönüşümsel Liderlik}

İlgili kavram literatürde farklı şekillerde adlandırılmışır. Dönüşümsel, transformasyonel, dönüşümcü, dönüştürücü gibi eş ve yakın anlamlı kelimelerle ifade edilen kavram, bu çalışmada dönüşümsel liderlik olarak isimlendirilmiştir.

Dönüşümsel liderliğin kökenine bakıldığında bu kavramı ilk olarak 1973 yılında Downston kullanmıştır (Chiang ve Wang,2012). 1978 yılına gelindiğinde tarihçi olan Burns tarafından kavramsal olarak ele alınmıştır. Burns (1978:20) bu liderliği “bir ya da birkaç kişinin izleyenleri veya birbirlerini daha yüksek motivasyona ve ahlâka teşvik etmeleri" olarak tanımlamıştır. Bu çerçevede dönüşümsel liderin ve lider ile astları arasındaki ilişkilerin özellikleri ahlâki açıdan incelenmiştir (Weiss ve Cropanzano,1996).

Literatürde liderlik ve özellikle son dönemlerde dönüşümsel liderlik ile ilgili birçok araştırma ve bu bağlamda çok sayıda tanım yapılmıştır. Bu tanımlardan bazıları aşağıda Tablo 1'de verilmiştir.

Tablo 1. Dönüşümsel liderlik tanımları*

\begin{tabular}{|l|l|}
\hline Araştırmacı & Tanım \\
\hline Burns (1978:20) & $\begin{array}{l}\text { "Bir ya da birkaç kişinin izleyenleri veya birbirlerini daha yüksek motivasyona ve ahlâka } \\
\text { teşvik etmeleri” }\end{array}$ \\
\hline Bass (1985) & $\begin{array}{l}\text { "Yenilik sağlayan, performansı artıran, misyon ve vizyon oluşturan, izleyicilerinin kişisel } \\
\text { gelişimini sağlayan bir liderlik davranışı” }\end{array}$ \\
\hline Bass (1990) & $\begin{array}{l}\text { "Takipçilerine yetki devri yapan ve örgütsel hedefleri takipçileriyle birlikte belirleyen bir } \\
\text { liderlik çeşidi” }\end{array}$ \\
\hline $\begin{array}{l}\text { Bass ve Avolio } \\
\text { (1990) }\end{array}$ & $\begin{array}{l}\text { “Takipçilerin değiştirildiği ve dönüştürüldüğü bir süreç olarak idealize edilmiş etki, } \\
\text { ilham verici motivasyon, entelektüel teşvik, bireysel ilgi gibi çıtıların oluştuğu, }\end{array}$ \\
\hline
\end{tabular}




\begin{tabular}{|c|c|}
\hline & $\begin{array}{l}\text { takipçilerin gelişimsel süreçlerini destekleyen ve motivasyonlarını artıran bir davranış } \\
\text { biçimi" }\end{array}$ \\
\hline $\begin{array}{l}\text { Podsakoff vd. } \\
\text { (1990) }\end{array}$ & $\begin{array}{l}\text { "Bir vizyon geliştirerek takipçilerin bu vizyonu kabul etmelerini sağlayan, yüksek } \\
\text { performans hedefleri belirleyerek bunları takipçilerine aktaran, takipçilerin bireysel } \\
\text { ihtiyaç ve duygularına ilgi gösteren, takipçilerin iş yapiş şekillerini yeniden } \\
\text { düşünmelerini sağlayan, takipçilerine olumlu geri bildirimde bulunarak onları } \\
\text { cesaretlendiren bir davranış biçimi" }\end{array}$ \\
\hline $\begin{array}{l}\text { Conger ve } \\
\text { Kanungo } \\
(1994)\end{array}$ & $\begin{array}{l}\text { "Takipçilerin karizmatik olarak anlamlandırdığı davranışlarla, takipçide sıra dışı bir } \\
\text { görev yapıyor algısı oluşturarak, ilham verici bir vizyon geliştiren ve böylece takipçilerin } \\
\text { itaat kapsamı sadece biçimsel otoriteden kaynaklı olmayan, liderlerini sıra dışı algılatan } \\
\text { bir davranış biçimi" }\end{array}$ \\
\hline $\begin{array}{l}\text { Korek, Felfe ve } \\
\text { Rothe (2010) }\end{array}$ & $\begin{array}{l}\text { "Çalışanların mevcut uygulama ve alışkanlıklarından vazgeçmek suretiyle yeni strateji } \\
\text { uygulama ve vizyona sahip olmaları" }\end{array}$ \\
\hline
\end{tabular}

*Seçili tanımlar ilgili literatürden derlenmiştir.

Bass (1990) ilgili durumun liderlerin işgörenlerinin çıkarlarını gözettiğinde, grubun amaçlarına ve misyonuna karşı bilinç oluşturduğunda ve grubun yararı için astlarında örgütün çıkarını kendi çıkarlarından daha önde tutma duygusu meydana getirdiklerinde ortaya çıktığını belirtmektedir. Bass (1985) bu konudaki araştırmalarını sanayi işletmeleri ve askeri örgütlerde gerçekleştirmiştir. Liderlik davranışlarına ilişkin geliştirdiği anketi ABD ordusunda görevli 176 kıdemli yöneticiye uygulamış ve beş faktör saptamıştır. Bunlar yaygın olarak kullanılan "Çok Faktörlü Liderlik Ölçeği" nin de temellerini oluşturan "koşullu ödül, istisnalarla yönetim, karizmatik liderlik, kişiselleşmiş ilgi ve entelektüel uyarımdan oluşmaktadır. Bunlardan ilk ikisi etkileşimsel son üçü ise dönüşümsel liderlikle ilgili faktörlerdir. Araştırma sonucuna göre üç dönüşümsel faktör, etkileşimsel etmenlere göre algılanan etkinlikle daha çok ilişkili bulunmuştur. Karizmatik, anlayışlı ve entelektüel açıdan destekleyici liderler diğerlerine göre daha fazla iş tatmini sağlamaktadırlar.

Dönüşümsel liderlerin fark yaratan bazı özellikleri bulunmaktadır: "çalışanların ihtiyaçlarını dikkate alan, değer yargılarını önemseyen, çalışanları değişime ve geleceğe hazırlayan, ileri görüşlü, çalışanlar arasında yakın ilişkiler kuran, çalışanlar arasında güven ve heyecanı destekleyen, çalışanlarına ilham kaynağı olan, risk alabilen, çalışanlar ve kurumun amaçları arasındaki ilişkileri belirleyen, amaçlar doğrultusunda sistemin yeniden yapılanmasına öncülük eden, sonuç odaklı ve her bir çalışanın kendisinin liderlik yönünü ortaya çıkarabilen kişiler" olarak bilinmektedir (Wang ve Lee,2009).

\section{Kişi-Örgüt Uyumu}

Kişi-örgüt uyumuna ilişkin çeşitli yaklaşımlar bulunmaktadır. Bunlar "bütünleyici uyum, ihtiyaçlar ve karşılananlar uyumu, beklenen kabiliyet uyumu, kişi-benlik uyumu, kişi-çevre uyumu, kişi-iş uyumu, kişigrup uyumu, kişi-yönetici uyumu, kişi-kültür uyumu ve kişi-etik iklim uyumu" şeklinde ifade edilebilir.

İlgili paradigma "Kişi-Çevre Uyumu" bağlamında kişi-iş uyumunun genişleyip incelenmesiyle literatürde kendisine yer bulan bir kavramdır. Chatman (1989) bireylerin değerleri, hedefleri, kişisel özellikleri ve davranışları gibi sahip oldukları kişisel olgular ile örgüt kültürü, örgütsel iklim, değerler, hedefler ve normlar gibi örgütsel olguların arasındaki uyumun kişi-örgüt uyumunu sağladığını belirtmiştir. Schneider vd. (1995) kişi-örgüt uyumunu "bireylerin kendi özellikleri ile örgütün sahip olduğu özellikler arasında yaşanabilecek sorunların ortadan kaldırılması ve mümkün olduğunca ortak bir zeminde buluşulması" olarak görmektedirler. Rynes vd. (2002)'nin de belirttiği gibi aday ve örgütün uyumluluk düzeyi, işgören seçim kararlarında gitgide artan öneme sahip bir kriter olmaya başlamıştır. Kristof-Brown vd. (2005)'nin de vurguladıkları gibi eğer iş tanımları bugünün iş dünyasında açık ve net olmayıp örgütler istihdam edecekleri adaylardan roller arasında rahat bir şekilde uyum sağlayabilme becerisi olanları istihdam altına almak 


\section{A. Sökmen - O. Benk 12/2 (2020) 1347-1357}

istiyorlarsa, iş gerekleri için yeterli olmaları ve örgüt kültürü ile de uyumlu olabileceklerin işe alınması büyük önem taşımaktadır.

Kişi-örgüt uyumunun kavramsallaştırılmasındaki paradigmalar yaklaşımın daha açık ve seçik olarak anlaşılmasına katkı sağlayabilir. Kişi-örgüt uyumunun bütünleyici (tamamlayıcı) uyum boyutu çalışanlar ve yöneticilerin (örgüt) ulaşmak istedikleri hedefler yâni bireysel ve örgütsel hedefler arasındaki uyumdur. Bütünleyici uyum içerisinde örgüte çalışanların seçilmesinde verimlilik ve örgütsel bağlllık gibi temel unsurlar dikkate alınmaktadır. Buradaki temel faktör örgütün kendi bünyesinde eksik gördüğü özellikleri tamamlayabilecek niteliklere sahip çalışanların örgütsel yapı içerisine dâhil edilmesini gerektirmektedir (Henderson,2010). Örgütsel hedefler liderlerin veya girişimcilerin değerlerini, vizyon ve misyonunu yansıtmaktadır. Hedeflerin uyumu konusunda yapılan bir çalışma olan Schneider (1987)'in ASA (AttractionSelection-Attrition /Çekme-Seçme-Yitirme) Modeli hedefleri örgütsel hedeflere benzeyen bireyler için örgütün çekici hâle getirilmesini ve bu sayede hem örgüt hedeflerinin hem de bireysel hedeflerin elde edilmesini öngörmektedir. Bu varsayımla birlikte birçok işletme çalışanlarına kendi hedeflerine dönük yatırımlar yapmaktadır. Yapılan bu yatırımların kişisel hedeflerle ne derece örtüştüğüne de bağlı olarak çalışanlar örgütün sunduğu bu imkânların etkisiyle işlerine ve işletmelerine karşı uyum davranışı sergilemektedirler. Kişi-örgüt uyumunun karşılayıcı uyum boyutu ise kişinin nitelikleri çevreyi tamamlar ya da çevrede eksik olanı karşılar mantığına dayanmaktadır. Karşılayıcı uyumluluk kendi içinde ikiye ayrılır: birinci boyutunda örgüt bireylerin ihtiyaçlarını, isteklerini, tercihlerini karşılar ve böylece uyum sağlanır. Bu boyutun karşısında istenilenler (Örneğin, çaba, bağlılık, deneyim vb.) -beceriler ilişkisi bulunmaktadır. Birey örgütün isteklerini karşılamak için gerekli becerilere sahip olduğunda uyumluluk sağlanmaktadır (Muchinsky ve Monahan,1987; Kristof,1996). Örgütün önemli kabul ettiği değerleri aynı zamanda çalışanların da önemli görmesi sonucunda değerlerde uygunluk meydana gelir. Kişilikte uygunluk ise çalışanların sahip oldukları kişilik özellikleri ile örgüt içerisindeki diğer çalışanların kişilik özellikleri arasındaki uyum düzeylerini ifade etmektedir (O'Reilly, Chatman ve Caldwell,1991).

Kişi-örgüt arasında yaşanan uyum eksikliği veya yetersizliği bireyin örgüte karşı negatif bir tutuma sahip olmasından işten ayrılmasına kadar uzanan bir dizi olumsuz duruma sebep olabildiği gibi, yüksek düzeyde kişi-örgüt uyumu olumlu örgütsel çıktıların elde edilmesini sağlamaktadır (Sekiguchi,2004). Yapılan araştırmalarda çalışanların kendi değerlerini yansıtan örgütlerde çalışmak istedikleri ve bu tür yapılara daha kolay uyum sağladıkları ortaya konmuştur. Dolayısıyla örgütlerin sahip oldukları çalışanların devir hızındaki azalma, iş tatmin düzeylerinin artması, örgüte olan bağlllık düzeylerinin ve müşterilerin memnuniyetlerinin artması gibi sonuçlar ancak çalışanların örgüt ile uyumlu olması sonucunda mümkün olmaktadır (Backhaus,2003).

\section{İş Tatmini}

Örgütsel Davranış ekolünde iş tatmini işyeri psikolojisi alanındaki en çok araştırılan değişkenlerden biridir ve çok sayıda psiko-sosyal sorun, iş dünyasının değişmesi, liderlikten iş tasarımına kadar değişen örgütsel faktörler ile ilişkilendirilmiştir (Park ve Kim,2009).

İlgili terim ilk defa 1911'de Gilbert ve Taylor tarafından "minimum stres ve yorgunluk yaratacak bir yöntemle fabrikada çalışmak" şeklinde tanımlanmıştır. I. Dünya Savaşı sonrası gelişmelerle ve Elton Mayo öncülügünde gerçekleştirilen Hawthorne Araştırmaları (1924-1933)'nda daha sistematik olarak ele alınmıştır. Hoppock'un 1935 yılında yayınlanan "Job Satisfaction" isimli makalesinden bugüne değin bu konu üzerinde ciddi çalışmalar yapılmaya devam edilmiştir (Yazıcıŏglu ve Sökmen,2007:2; Judge vd.,2008).

İş tatmini kavramı uzun senelerden bu yana sıklıkla üzerinde çalışılan bir tutumdur. Konu ile ilgili çok sayıda araştırma yapılmış ve tanım ortaya konmuştur. Bu tanımlardan bazıları Tablo 2' de sunulmuştur. 
Tablo 2. İş tatmini tanımları*

\begin{tabular}{|c|c|}
\hline Araştırmacı & Tanım \\
\hline Vroom (1964:99) & "Çalışanların iş rollerine yönelik duygusal yönelimleri ya da tepkileri" \\
\hline $\begin{array}{lr}\text { Schneider ve } \\
\text { Snyder }(1975: 319)\end{array}$ & $\begin{array}{l}\text { "Çalışanın işle ilgili (Örneğin, işin kendisi, liderin davranışları vb.) ya da iş sahibi } \\
\text { olmanın sonuçları (Örneğin, maaş, güvence vb.) ile ilgili kişisel değerlendirmesi ve işe } \\
\text { dâir çalışanın kendi iç değer yargılarından (Örneğin, değer, norm, beklenti vb.) } \\
\text { süzülmüş algıları" }\end{array}$ \\
\hline $\begin{array}{l}\text { Hackman ve } \\
\text { Oldham (1976) }\end{array}$ & "Çalışanların işlerinden mutluluk duyması" \\
\hline Locke $(1976: 1304)$ & $\begin{array}{l}\text { "Bireyin iş ya da iş tecrübelerinden kaynaklanan keyifli veya olumlu duygusal } \\
\text { durumu" }\end{array}$ \\
\hline $\begin{array}{l}\text { Mudor ve } \\
\text { Tooksoon (2011) }\end{array}$ & "Bireylerin çalışmakta oldukları iş yerinden memnun olma düzeyleri" \\
\hline
\end{tabular}

*Seçili tanımlar ilgili literatürden derlenmiştir.

Çalışanların işe ve örgüte karşı tutumu, işlerinin onların ihtiyaçlarını ve değerlerini doğrudan ya da dolaylı olarak elde etmelerini sağladığını fark ettiklerinde iş tatmini meydana gelmektedir. İş tatmini çalışanın işle ilgili beklentileri ile sahip oldukları arasındaki farkı temsil etmektedir. Bu fark ne kadar artarsa memnuniyetsizlik de o kadar fazla olmaktadır (Larson ve Luthans,2006).

Bireylerin becerileri, becerilerini kullanma durumları, yapmakta oldukları görevlerin önem derecesi, bağımsızlıkları, sorumluluk ve başarıları, işin istikrarlı olması ve sosyal statü gibi durumlar çalışanların duygularını etkilemekte ve bu durum da tatmini ortaya çıkarmaktadır (Bogler,2001; González, Sánchez ve López-Guzmán,2016).

\section{Yöntem}

Araştırmanın amacı dönüşümsel liderlik (DL), kişi-örgüt uyumu (KÖU) ve iş tatmini (ITT) değişkenleri ilişkisini bakanlık çalışanları örnekleminde ele almaktır. Bu doğrultuda araştırma hipotezlerinin de yer aldığı ve teorik çerçeveye uygun olarak değişkenler arasındaki ilişkileri ortaya koymak üzere aşağıdaki model tasarlanmıştır (Şekil 1).

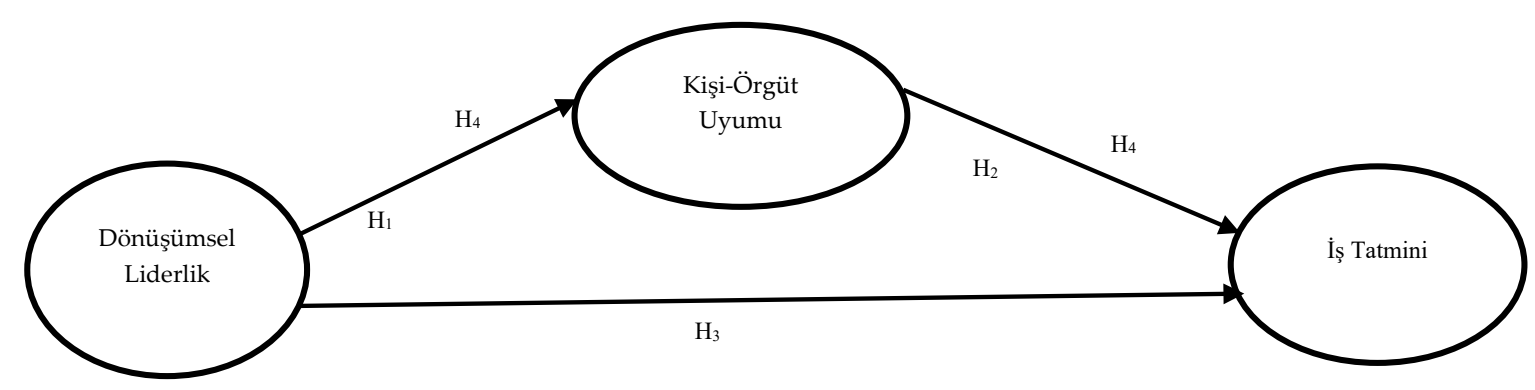

Şekil 1: Araştırmanın Modeli

Şekil 1'de verilen model ve ilgili literatür bağlamında hipotezlerin dayanakları ve hipotezler şu şekildedir: 


\section{A. Sökmen - O. Benk 12/2 (2020) 1347-1357}

Dönüşümsel liderler örgütsel hedefleri takipçileriyle birlikte saptamakta (Bass,1990), çalişanlar ve örgütün amaçları arasındaki ilişkileri belirlemekte ve böylece bir uyum ortamı oluşturmaktadırlar (Wang ve Lee,2009). Dönüşümsel liderliğin grup verimine etkisi izleyicilerin örgütün değerleri ile algıladıkları uyumlarına bağlıdır (Hoffman vd.,2011):

\section{H1: Çalı̧̧anların dönüşümsel liderlik algılarının kişi-örgüt uyumu düzeylerine anlamlı etkisi vardır.}

Kişi-örgüt arasında yaşanan uyum yetersizliği ya da eksikliği bireyin örgüte karşı negatif bir tutuma sahip olmasından işten ayrılmasına kadar uzanan bir dizi olumsuz tutum ve davranışa sebep olabildiği gibi, yüksek düzeyde kişi-örgüt uyumu ise olumlu örgütsel çıktıların elde edilmesini sağlamaktadır (Sekiguchi,2004). Meglino, Ravlin ve Adkins (1989) çalışanlar ile yönetici değerlerinin uyumlu olması durumunda daha yüksek düzeyde tatmin sağlandığını; Chatman (1991) çalışan ile örgüt değerlerinin uyumlu olması sonucunda iş tatmininin yüksek olacağını; O'Reilly, Chatman ve Caldwell (1991) ise oluşan kişi-örgüt uyumunun çalışan açısından gelecek dönem tatmininin belirleyicisi olabileceğini ortaya koymuşlardır. Netemeyer vd. (1997) ve Van Dyne, Graham ve Dienesch (1994)'in araştırma bulgularının da desteklediği gibi kişi-örgüt uyumu iş tatmini üzerinde güçlü bir etkiye sahiptir. Lauver ve Kristof-Brown (2001) da kişi-örgüt uyumunun iş tatmini üzerinde etkili olduğunu ortaya koymuşlardır:

$H_{2}$ : Çalışanların kişi-örgüt uyumunun iş tatmini düzeylerine anlamlı etkisi vardır.

Dönüşümsel liderlik ile çalışanların iş tatmini arasında pozitif yönlü ve istatistikî açıdan anlamlı bir ilişki vardır (Podsakoff vd.,1990; Saleem,2015). Dönüşümsel liderlik iş tatmininin iyi bir belirleyicisidir. Dönüşümsel liderlik çalışanların iş tatminlerini arttırmada önemli bir rol oynamaktadır (Ho vd.,2016). Dönüşümsel liderler karakteristik niteliklerini öne çıkararak çalıştıkları örgütlerde inovatif bir yönetim paradigması oluşturmakta ve bunun sonucu olarak da örgütsel performansı artırmaktadırlar. Örgütte yaşanan bu değişim işgörenler üzerinde de pozitif bir tesir oluşturmakta ve iş tatmin düzeylerinin yükselmesini sağlamaktadır (Voon vd.;2001).

$\mathrm{H}_{3}$ : Çalışanların dönüşümsel liderlik algllarının iş tatmini düzeylerine anlamlı etkisi vardır.

H4: Çalışanların dönüşümsel liderlik algılarının iş tatmini üzerindeki etkisinde kişi-örgüt uyumunun aracı bir etkisi vardır.

Araştırma bir bakanlığın bir biriminin personeline yönelik olarak 2019 yılı Ekim-Aralık dönemleri arasında gerçekleştirilmiştir. Bu dönemde ilgili birimdeki çalışan sayısı toplam 1233'dür ve toplamda 560 tane kullanılabilir anket formu elde edilmiştir. Bu bağlamda seçilen örneklem evrenin yaklaşık \% 45'ini temsil etmektedir.

Araştırmada katılımcıların dönüşümsel liderliğe ilişkin algılarını ölçmek için Bass ve Avolio (1995) tarafından oluşturulan yirmi maddelik Çok Faktörlü Liderlik Ölçeği kullanılmıştır. İş tatmini Agho, Price ve Mueller (1992) tarafından geliştirilmiş olan altı maddelik İş Tatmini Ölçeği ile kişi-örgüt uyumu ise Netemeyer, Boles, McKee ve McMurrian (1997) tarafından geliştirilen dört maddeli ölçek ile ölçülmüştür. Araştırmada kullanılan ölçeklerin tamamı 5'li Likert tipinde hazırlanmıştır ve her madde 1 ile 5 arasında (1=Hiç Katılmıyorum ve 5=Tamamen Katılıyorum) derecelendirilmiştir. Ölçekler hem elektronik ortamda, hem de elden dağıtılarak yüksek katılım elde edilmesine çalışılmıştır.

\section{Bulgular}

Araştırma sonucunda elde edilen veri seti SPSS 26 programında değerlendirilmiştir. Demografik özelliklere ilişkin veriler frekans analizi ve yüzdesel değerler ile açıklanmıştır. Ölçekler için Cronbach's Alfa güvenirlik analizi yapılmıştır. Hipotez testleri için korelasyon ve regresyon analizleri yapılmıştır.

Araştırmaya 317 kadın ve 243 erkek katılmıştır, bunların \% 69'u evli, \% 29'u bekâr, \% 2'si dul/boşanmış durumdadır. Katılımcıların \% 14'ü 22-30, \% 37'si 31-39, \% 49'u 40 yaş ve üzerindedir. Katılımcıların \% 12'si lise, \% 69'u lisans, \% 19'u yüksek lisans ve üstü mezunudur. Katılımcıların \% 25'i 1-10 yıl arası, \% 36'sı 11-20 yıl arası, \% 39'u 21 yıl ve üzeri mesleki kıdeme sahiptir. Araştırmada sorulara gerçekçi cevaplar alınması kapsamında katılımcıların unvan bilgileri istenmemiştir. 
Tablo 3. Değişkenlerin Güvenilirlik Katsayıları ve Korelasyon Değerleri

\begin{tabular}{|l|l|l|l|}
\hline & $D L$ & KÖU & ITT \\
\hline Dönüşümsel Liderlik (DL) & {$[0.94]$} & & \\
\hline Kişi-Örgüt Uyumu (KÖU) &, $423^{* *}$ & {$[0.92]$} & \\
\hline İş Tatmini (̇ंT) &, $429^{* *}$ &, $451^{* *}$ & {$[0.92]$} \\
\hline
\end{tabular}

**Korelasyon 0.01 düzeyinde anlamlı (iki yönlü), [Parantez içindeki değerler Cronbach Alfa güvenilirlik katsayısıdır.]

Araştırmada kullanılan ölçeklerin güvenilirlik değerleri şöyledir; dönüşümsel liderlik ölçeği 0.94, kişi-örgüt uyumu ölçeği 0.92 ve iş tatmini ölçeği 0.92 'dir. Bu değerler ölçeklerin güvenilirlik katsayılarının kabul edilebilir ölçüde yüksek olduğunu göstermektedir. Değişkenler arası ilişkileri göstermek amacıyla korelasyon analizi yapılmıştır. Analiz sonucunda dönüşümsel liderlik ile kişi-örgüt uyumu arasında pozitif yönde anlamlı bir ilişki $(\mathrm{r}=0.423, \mathrm{p}<0.01)$ ve dönüşümsel liderlik ile iş tatmini arasında pozitif yönde anlamlı bir ilişki $(\mathrm{r}=0.429, \mathrm{p}<0.01)$ bulunmuştur. Kişi-örgüt uyumu ile iş tatmini arasında da pozitif yönde anlamlı bir ilişki $(\mathrm{r}=0.451, \mathrm{p}<0.01)$ bulunduğu tespit edilmiştir.

Tablo 4. Regresyon Değerleri

\begin{tabular}{|c|c|c|c|c|}
\hline \multirow{2}{*}{$\begin{array}{l}\text { Bă̆ımsız Değişken } \\
\text { Dönüusüumsel Liderlik }\end{array}$} & \multicolumn{4}{|c|}{ Bă̆ımlı Değişkenler } \\
\hline & \multicolumn{2}{|c|}{ Kişi-Örgüt Uуumu } & \multicolumn{2}{|c|}{ İş Tatmini } \\
\hline & $\bar{\beta}$ & $p$ & $\bar{\beta}$ & $p$ \\
\hline & 0,423 & 0,000 & 0,429 & 0,000 \\
\hline & \multicolumn{2}{|c|}{$\begin{array}{l}\mathbf{R}^{2}=0.179 \\
\mathbf{F}=95,669\end{array}$} & \multicolumn{2}{|c|}{$\begin{array}{l}\mathbf{R}^{2}=0,184 \\
\mathbf{F}=98,985\end{array}$} \\
\hline \multirow[t]{4}{*}{ Kişi-Örgüt Uyumu } & \multicolumn{2}{|c|}{ İş Tatmini } & & \\
\hline & $\beta$ & $p$ & & \\
\hline & 0,451 & 0,000 & & \\
\hline & \multicolumn{2}{|c|}{$\begin{array}{l}R^{2}=0,203 \\
F=111,699\end{array}$} & & \\
\hline
\end{tabular}

Regresyon analizi sonuçlarına göre dönüşümsel liderliğin kişi-örgüt uyumu üzerinde anlamlı bir etkisinin olduğu ( $(=0.423 ; p<0,001)$ ve \% 17,9 oranında açılayıcı olduğu $\left(R^{2}=0.179\right)$, iş tatmini üzerinde de anlamlı bir etkisinin olduğu $(\Omega=0.429 ; \mathrm{p}<0,001)$ ve $\% 18,4$ oranında açılayıcı olduğu $\left(\mathrm{R}^{2}=0.184\right)$ görülmektedir. Dolayısıyla Hipotez 1 ve 3 kabul edilmiştir. Buna göre bakanlık personelinin dönüşümsel liderlik algılarının artması durumunda kişi-örgüt uyumu ve iş tatmini düzeylerinin artacağı görülmektedir. Bununla birlikte kişi-örgüt uyumunun da iş tatmini üzerinde anlamlı bir etkisinin olduğu ( $(=0.451 ; p<0,001)$ ve $\% 20,3$ oranında açılayıcı olduğu $\left(R^{2}=0.203\right)$ görülmektedir. Dolayısıyla Hipotez 2 de kabul edilmiştir. Buna göre bakanlık personelinin kişi-örgüt uyumlarının artması durumunda iş tatmini düzeylerinin artacağı rahatlıkla ifade edilebilir.

Dönüşümsel liderliğin iş tatmini üzerindeki etkisinde kişi-örgüt uyumunun aracılık rolünün belirlenmesinde aracı değişken analizi yöntemi (Baron ve Kenny,1986; Hayes,2009) kullanılmıştır. Bu yöntemde aracılık rolü üç değişkenli model oluşturularak belirlenebildiği için bu araştırmada buna uygun bir model oluşturulmuştur. Buna göre dönüşümsel liderliğin iş tatmini üzerindeki etkisinde kişi-örgüt uyumunun aracı etkisine yönelik aşağıdaki model test edilmiştir: 


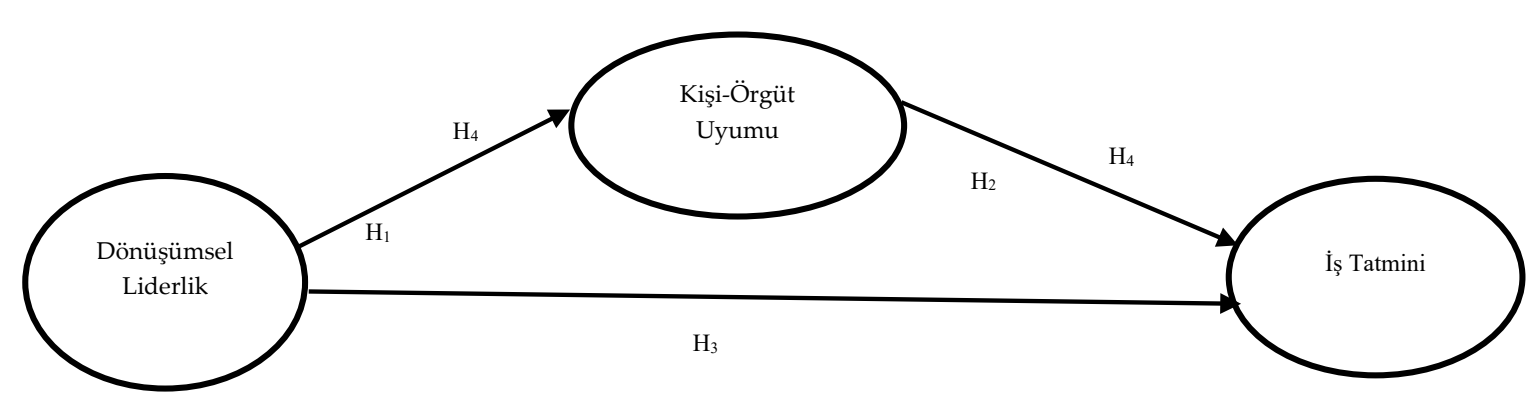

Şekil 2. Aracı Değişken Modeli

Modeldeki regresyon analizi sonuçlarına göre birinci adımda dönüşümsel liderliğin kişi-örgüt uyumu üzerinde anlamlı bir etkisinin ( $B=0.423 ; \mathrm{p}<0,001)$ olduğu; ikinci adımda ise dönüşümsel liderliğin iş tatmini üzerinde de anlamlı bir etkisinin ( $(=0.429 ; \mathrm{p}<0,001)$ olduğu; daha sonra kişi-örgüt uyumunun da iş tatmini üzerinde anlamlı bir etkisinin $(\Omega=0.451 ; \mathrm{p}<0,001)$ olduğu tespit edilmiştir. Son olarak dönüşümsel liderlik ve kişi-örgüt uyumu birlikte analize dâhil edilmiştir; iş tatmini üzerindeki etkilerine bakılmıştır. Buna göre dönüşümsel liderlik ve kişi-örgüt uyumunun analize sokulmasıyla iş tatmini üzerinde dönüşümsel liderliğin pozitif ve anlamlı etkisi devam etmiş ancak etki katsayısı azalmıştır $(ß=0.291 ; p<0,001)$. Kişi-örgüt uyumununda iş tatmini üzerindeki pozitif ve anlamlı etkisi devam etmiş fakat etki katsayısı azalmıştır $(B=0.328 ; p<0,001)$. Buna göre dönüşümsel liderliğin iş tatmini üzerindeki etkisinde kişi-örgüt uyumunun kısmi aracılık etkisinin olduğu görülmektedir. Dolayısıyla Hipotez 4 kabul edilmiştir.

\section{Sonuç ve Öneriler}

Katılımcıların dönüşümsel liderlik algılarının, kişi-örgüt uyumu ve iş tatmini düzeylerinin kabul edilebilir seviyede yüksek olduğu bulgularına ulaşılmıştır. İlgili literatür incelendiğinde ilgili değişkenler ile ilgili yapılan araştırmalarda da benzer sonuçlara ulaşılmıştır (Koç,2011; Koç ve Yazıcıŏlu,2011; Bıyık, Şimşek ve Sökmen,2016; Mete, Sökmen ve Bıyık, 2016; Sökmen ve Aydıntan, 2016; Sökmen ve Aksoy,2017; Aypar, Sökmen ve Ekmekçioğlu,2018).

Bakanlık personelinin dönüşümsel liderlik algılarının artması durumunda kişi-örgüt ve iş tatmini düzeylerinin artacağı görülmektedir. Katılımcıların kişi-örgüt uyumu düzeylerinin artması durumunda iş tatmini düzeylerinin artacağı rahatlıkla ifade edilebilir. Dönüşümsel liderliğin iş tatmini üzerindeki etkisinde kişi-örgüt uyumunun kısmi aracılık etkisinin olduğu görülmektedir. Kişi-örgüt uyumunun kısmi aracılık etkisinin var olması iş tatmini ile dönüşümsel liderlik arasında başka bir değişkenin de aracılık yapabileceğini göstermektedir. Bir başka ifade ile çalışanların iş tatminlerinin sağlanması çeşitli motivasyon teorilerinin de ortaya koyduğu gibi farklı şekillerde olabilmektedir. Bu anlamda kişi-örgüt uyumu iş tatmininin etki altına alınmasında dönüşümsel liderliğe katkı sunmaktadır. Bir bakanlıkta görev yapan 560 kamu çalışanından elde edilen bulgular değerlendirildiğinde merkezi ve özellikle taşra teşkilat yönetiminin çağın gerektirdiği dönüşümsel çabalarla birlikte çalışanların kişi-örgüt uyumlarını dikkate almaları ve iş tatmin düzeylerini artırmaya yönelik eylemlerde bulunmaları gerektiği düşünülmektedir.

Hızla değişen ve dönüşen dünyada, örgütlerin de bu duruma ayak uydurabilmeleri için liderlerin çalışanlarına destek olmaları gerekmektedir. Örgütün değerleri ile uyumlu bir şekilde eylemde bulunan ve diğer çalışanların iş tatmini duymaları için çaba gösteren bir lider örgütün işleyişine şüphesiz katkı sunacaktır. Bu bağlamda bir lider maddi ve manevi açıdan izleyenlerinin çalışma ortamında veya dışında kendilerine destek olabilir. Örneğin, izleyeninin kişisel bir sorununa eğilen, onu öven, ona rehberlik eden bir lider çalışanın iş tatminine yadsınmayacak düzeyde etki edebilir.

Kamu örgütleri katı bürokratik yapılarını kırmaları ve çağın gereklerine ayak uydurmaları için işe alım sürecinde adaylardan talep edilen iş gereklerine çok iyi odaklanmalıdırlar. Kontrol odaklı bir yaklaşımla sürecin en başından itibaren örgütleri ile uyumlu olan veya bunun geliştirilebileceğine inandıkları kişileri seçmelidirler. Bu bağlamda sadece kamuya dair sınav yapısına ek olarak birçok çağdaş testten faydalanmaları etkinlik açısından son derece önemli olacaktır. Sonuç olarak örgütün değer yapısı ve iş gerekleri ile uyum içerisinde olan bir çalışanın iş tatmini duyması kolaylaşacaktır.

Gerçekleşen araştırma bir bakanlığın merkez birimi ile sınırlıdır. Bu yüzden sadece bir kamu kurumunun tek biriminde yapılan bu çalışmanın bilimsel araştırma merceğinde genelleyebilir bir özellik taşımadı̆̆ı gözden 


\section{A. Sökmen - O. Benk 12/2 (2020) 1347-1357}

kaçırılmamalıdır. Gelecek çalışmalar için işgücü çeşitliliğine de sahip kamu veya özel örgütler arasında karşılaştırmalı olarak değişkenlerin tekrar ele alınması literatüre katkı sunulması adına faydalı olacaktır.

\section{Kaynakça}

Agho, A. O., Price, J. L., and Mueller, C. W. (1992). Discriminant validity of measures of job satisfaction, positive affectivity and negative affectivity. Journal of Occupational and Organizational Psychology, 65(3), 185-196.

Aypar, S., Sökmen, A. ve Ekmekçioğlu, E.B. (2018). İş Tatmini ve İşten Ayrılma Niyeti İlişkisi: Örgütsel Özdeşleşmenin Aracılık Rolü. Gazi Üniversitesi Sosyal Bilimler Dergisi, 5(13), 116-124.

Backhaus, K. (2003). Importance of Person-Job Fit to Job Seekers, Career Development International ,8(1), 2126.

Baron, R. M., and Kenny, D. A. (1986). The moderator-mediator variable distinction in social psychological research: Conceptual, strategic, and statistical considerations. Journal of personality and social psychology, 51(6), 1173-1182.

Bass, B. M. (1985). Leadership: Good, Better, Best. Organizational Dynamics, 13(3), 26-40.

Bass, B. M. (1990). From Transactional To Transformational Leadership: Learning To Share The Vision. Organizational Dynamics, 18(3), 19-31.

Bass, B. M., and Avolio, B. J. (1990). The implications of transactional and transformational leadership for individual, team, and organizational development. Research in organizational change development, $4(1), 231-272$.

Bass, B. M., and Avolio, B. J. (1995). MLQ Multifactor Leadership Questionnaire, Leader Form, Rater Form, and Scoring. California. Palo Alto, CA: Mind Garden.

Bıyık, Y., Şimşek, T. ve Sökmen, A. (2016). Etik İklimin İş Tatmini ve İşten Ayrılma Niyetine Etkisinde Örgütsel Bağlllı̆̆ın Aracı Rolü: Bir Holdingin Yöneticilerine Yönelik Araştırma. Eurasian Academy of Sciences Social Sciences Journal, 1, 237-249.

Bogler, R. (2001). The Influence of Leadership Style on Teacher Job Satisfaction, Educational Administration Quarterly, 37(5), 662-683.

Burns, J. M. (1978). Leadership, New York: Harper and Row.

Chatman, A.J.(1989). Improving Interactional Organizational Research: A Model of Person-Organization Fit, Academy of Management Review, 14(3), 333-349.

Chatman, A.J. (1991). Matching People and Organizations: Selection and Socialization in Public Accounting Firms, Administrative Science Quarterly, 36(3), 459-484.

Chiang, C.F. and Wang, Y.Y. (2012). The Effects of Transactional and Transformational Leadership on Organizational Commitment in Hotels: the Mediating Effect of Trust, Journal of Hotel and Business Management, 1(1), 1-11.

Conger, J. A., and Kanungo, R. N. (1994). Charismatic leadership in organizations: Perceived behavioral attributes and their measurement. Journal of Organizational Behavior, 15(5), 439-452.

Dyne, V.L., Graham, J. W., and Dienesch, R. M.(1994). “Organizational Citizenship Behavior: Construct Redefinition, Measurement, and Validation", Academy of Management Journal, 37(4), 765-802.

González, F., Sánchez S. M. and López-Guzmán T. (2016). The Effect of Educational Level on Job Satisfaction and Organizational Commitment: A Case Study in Hospitality, International Journal of Hospitality \& Tourism Administration, 17(3), 243-259.

Hackman, J.R. and Oldham, G.R. (1976). Motivation through the design of work: test of a theory, Organizational Behavior and Human Performance, 16(3), 250-279. 


\section{A. Sökmen - O. Benk 12/2 (2020) 1347-1357}

Hayes, A. F. (2009). Beyond Baron and Kenny: Statistical mediation analysis in the new millennium. Communication Monographs, 76(4), 408-420.

Henderson, J.C. (2010). Sharia-Compliant Hotels. Tourism and Hospitality Research, 10(3), 246-254.

Ho, V.T., Dinh, T.L., and Vu, M.C. (2016). "Transformational and Transactional Leadership Styles and Employees' Job Satisfaction in Vietnamese Local Companies", International Review of Management and Business Research, 5(3), 938-950.

Hoffman, B. J., Bynum, B. H., Piccolo, R. F. ve Sutton, A. W. (2011). Person- Organization Value Congruence: How Transformational Leaders Influence Work Group Effectiveness. Academy of Management Journal, 54(4), 779-796.

Judge, T.A., Heller, D. and Klinger, R. (2008). The Dispositional Sources Of Job Satisfaction: A Comparative Test. Applied Psychology: An International Review. 57(3), 361-372.

Koç, H. (2011). The impact of managers' leadership behaviors on job satisfaction and performance of employees. African Journal of Business Management, 5(30), 11836-11843.

Koç, H. ve Yazıcıoğlu, İ. (2011). Yöneticiye Duyulan Güven İle İş Tatmini Arasındaki İlişki: Kamu ve Özel Sektör Karşılaştırılması. Doğuş Üniversitesi Dergisi, 12/1(46-57).

Korek, S., Felfe, J. and Rothe, U.Z. (2010). Transformational Leadership and Commitment: A Multilevel Analysis of Group-Level Influences and Mediating Processes, European Journal of Work and Organizational Psychology, 19 (3), 364-387.

Kristof, A.L. (1996). Person-organization fit: an integrative review of its conceptualizations, mesaurement and implications, Personnel Psychology, 49(1), 1-49.

Kristof-Brown, A. L., Zimmerman, R. D., and Johnson, E. C. (2005). Consequences of Individuals' Fit at Work: A Meta-Analysis of Person-Job, Person-Organization, Person-Group, and Person-Supervisor Fit, Personnel Psychology, 58(2), 281-342.

Larson, M., and Luthans, F. (2006). Potantial Added Value of Psychological Capital in Predicting Work Attitudes, Journal of Leadership and Organizational Studies, 13(1), 45-62.

Lauver, K. J., and Kristof-Brown, A.(2001). “Distinguishing between Employees' Perceptions of Person-Job and Person-Organization Fit", Journal of Vocational Behavior, 59(3), 454-470.

Locke, E.A.(1976). The nature and causes job satisfaction. (Edit. M. D. Dunnette). Handbook Of Industrial and Organizational Psychology, Chicago: Rand McNally, (pp. 1297-1343).

Meglino, B. M., Ravlin, E. C., Adkins, C.L. (1989). A work values approach to corporate culture: A field test of the values congruence process and its relationship to individual outcomes. Journal of Applied Psychology, 74 (3), 424-432.

Mete, E. S., Sökmen, A. ve Biylk, Y. (2016). The Relationship beetween Organizational Commitment, Organizational Identification, Person-Organization Fit and Job Satisfaction: A Research on IT Employees. International Review of Management and Business Research, 5(3), 870-901.

Muchinsky, P.M. and Monahan, C.J.(1987).“What is Person-Environment Congruence? Supplementary versus Complementary Models of Fit", Journal of Vocational Behavior, 31(1), 268-277.

Mudor, H., and Tooksoon, P. (2011). Conceptual Framework On The Relationship Between Human Resource Management Practices, Job Satisfaction, And Turnover, Journal of Economics and Behavioral Studies, 2(2), 41-49.

Netemeyer, R., Boles, J., McKee, D., and McMurrian, R. (1997). An Investigation into the Antecedents of Organizational Citizenship Behaviors in a Personal Selling Context. Journal of Marketing,61(3), 85-98. 
O'Reilly, C. A., Chatman, J., and Caldwell, D. F. (1991). People and organizational culture: A profile comparison approach to assessing person-organization fit. Academy of Management Journal, 34(3), 487-516.

Park, J. S., and Kim, T. H. (2009). Do Types Of Organizational Culture Matter in Nurse Job Satisfaction and Turnover Intention?, Leadership in Health Services, 22 (1), 20-38.

Podsakoff, P. M., MacKenzie, S. B., Moorman, R. H., and Fetter, R. (1990). Transformational leader behaviors and their effects on followers' trust in leader, satisfaction, and organizational citizenship behaviors. The leadership quarterly, 1(2), 107-142.

Rynes, S. L., Brown, K. G. and Colbert, A. E.(2002). “Seven Common Misconceptions about Human Resource Practices: Research Findings Versus Practitioner Beliefs", Academy of Management Executive, 16(3), 92-103.

Saleem, H. (2015). "The impact of leadership styles on job satisfaction and mediating role of perceived organizational politics", Procedia - Social and Behavioral Sciences, 172, 563 - 569.

Schneider, B., and Snyder, R.A., (1975). some relationships between job satisfaction and organization climate. Journal of Applied Psychology, 60(3), 318-328.

Schneider, B. (1987). "The people make the place", Personnel Psychology, 40(3), 437-453.

Schneider, B., Goldstein, H. W., and Smith, D. B.(1995). The ASA framework: An update, Personnel Psychology, 48(4), 747-773.

Sekiguchi T. (2004). "Person-Organization Fit And Person-Job Fit in Employee Selection: A Review of The Literature". Osaka Keidai Ronshu, 54(6), 179-196.

Sökmen, A. ve Aksoy, E.M. (2017). Dönüşümcü Liderliğin AR-GE Performansına Etkisi: Türkiye Savunma Sanayi Sektöründe Bir Çalışma. Üçüncü Sektör Sosyal Ekonomi, 52 (1), 84-101.

Sökmen, A. ve Aydıntan, B.(2016). Kariyer Geleceği Algısının İş Tatmini ve İşten Ayrılma Niyetine Etkisi: Bir Kamu Kurumunda Araştırma. ISARDER, 8(3), 251-263.

Voon, M.,L., Lo, M.C., Ngui, K.S., Ayob, N.B. (2011). “The influence of leadership styles on employees' job satisfaction in public sector organizations in Malaysia", International Journal of Business, Management and Social Sciences, 2(1), 24-32.

Vroom, V.H. (1964). Work and motivation. Oxford, England: Wiley.

Wang, G., and Lee, P. D. (2009). Psychological empowerment and job satisfaction: An analysis of interactive effects. Group and Organization Management, 34(3), 1-26.

Weiss, H. M., and Cropanzano, R. (1996). Affective events theory: A theoretical discussion of the structure, causes and consequences of affective experiences at work. Staw, Barry M. (Ed); Cummings, L. L. (Ed). Research in Organizational Behavior, 18, 1-74.

Yazıcıoğlu, İ. ve Sökmen, A. (2007). Otel İşletmelerinin Yiyecek-İçecek Departmanlarında Görev Yapan İşgörenlerin İş Tatmin Düzeylerinin Değerlendirilmesi: Adana'da Bir Uygulama. Muğla Üniversitesi Sosyal Bilimler Enstitüsü Dergisi, Sayı 18, 1-23. 